\title{
Castration-resistant prostate cancer: potential targets and therapies
}

This article was published in the following Dove Press journal:

Biologics:Targets and Therapy

2I August 2012

Number of times this article has been viewed

\author{
Aijaz Parray' \\ Hifzur R Siddique' \\ Sanjeev Nanda ${ }^{1,2}$ \\ Badrinath R Konety ${ }^{3}$ \\ Mohammad Saleem ${ }^{1,3,4}$ \\ 'Molecular Chemoprevention and \\ Therapeutics, The Hormel Institute, \\ University of Minnesota, Austin, \\ ${ }^{2}$ Department of Internal Medicine, \\ Mayo Clinic Health Systems, \\ Austin, ${ }^{3}$ Department of Urology, \\ University of Minnesota, Minneapolis, \\ ${ }^{4}$ Department of Laboratory Medicine \\ and Pathology, University of \\ Minnesota, Minneapolis, Minnesota, \\ USA
}

\begin{abstract}
The treatment landscape for patients with castration-resistant prostate cancer (CRPC) is undergoing significant changes with the advent of new therapies and multidisciplinary efforts by scientists and clinicians. As activation of multiple molecular pathways in the neoplastic prostate makes it impossible for single-target drugs to be completely effective in treating CRPC, this has led to combination therapy strategy, where several molecules involved in tumor growth and disease progression are targeted by a therapeutic regimen. In the present review, we provide an update on the molecular pathways that play an important role in the pathogenesis of CRPC and discuss the current wave of new treatments to combat this lethal disease.
\end{abstract}

Keywords: chemoresistance, CRPC, molecular pathways, neoplastic prostate

\section{Introduction}

The pathogenesis of castration-resistant prostate cancer (CRPC) in human patients is complex. As yet, no definite mechanism has been proposed that is responsible for driving the progression of disease from a treatable hormone-dependent condition to untreatable CRPC. While several studies point to a progression of CRPC from hormone-dependent phenotype, there are reports suggesting that CRPC and hormonedependent disease develop simultaneously and independent of each other in patients. This phenomenon could be related to the activation of multiple signaling pathways in tumor tissues. The identification of causative or contributive molecular pathways has high relevance for the development of new target-based therapeutic agents to treat CRPC. In the current review, we discuss several molecular pathways that have been reported to play critical roles in the pathogenesis of CRPC and are being pursued as drug targets.

\section{The androgen receptor (AR) and CRPC Role in etiology of disease}

In the majority of prostate cancer $(\mathrm{CaP})$ cases, the $\mathrm{AR}$ has been found to be a principal driver of disease progression, although some exceptional $\mathrm{CaP}$ cases do exist in which prostatic tumors are not linked to AR signaling. ${ }^{1,2} \mathrm{CaP}$ begins as an androgendependent disease, which is managed by a series of therapies that suppress AR signaling by androgen depletion and/or the administration of AR antagonists. ${ }^{3}$ However, the regression of tumor growth brought about by these therapies is usually only temporary and, after a short remission period, prostate tumors often regrow and become resistant to therapy. At this stage, the tumors are described as "androgen independent" or 
"castration-resistant" (ie, CRPC). Recent studies have shown that increased expression of the AR is the most common event associated with CRPC cell growth. ${ }^{4}$ Further, accumulating evidence suggests that during the progression of $\mathrm{CaP}$ to CRPC, phenotype could be attributed to the restoration of AR signaling in surviving $\mathrm{CaP}$ cells in patients receiving antihormone therapy. ${ }^{4}$

CRPC emergence has been attributed to a variety of mechanisms, including activation by receptor tyrosine kinases from growth factors, loss of cell-cycle regulators, and, in some cases, genomic mutations in the AR allowing response to nonspecific AR ligands. ${ }^{5}$ During CRPC emergence, $\mathrm{CaP}$ cells develop a multitude of mechanisms to activate AR. ${ }^{6}$ These include $A R$ gene amplification, overexpression of AR co-activators and ligand-independent activation of AR in an androgen-depleted environment. ${ }^{7,8}$ This is based on studies showing that $A R$ gene mutation and amplifications resulting in elevated AR protein expression are detected in the majority of metastatic prostatic tissues in CRPC patients. ${ }^{9}$ Consistent with these clinical observations, $A R$ gene mutation, amplification, and protein overexpression are commonly observed in the majority of $\mathrm{CaP}$ cell lines derived from CRPC patients. ${ }^{9}$ Some prostate tumors are reported to become truly androgenindependent by activating survival pathways that allow the tumor cells to survive in the absence of AR signaling. There is some consensus that even after androgen ablation therapy, a low concentration of androgens released from the adrenal gland and biosynthesized within tumors sustain the AR activation and proliferation of remaining tumor cells in CRPC patients. ${ }^{9,10}$

The discovery of AR splice variants has given another important dimension to the significance of AR in CRPC. ${ }^{11,12}$ AR splice variants have been observed in CaP cell lines. ${ }^{11,12}$ AR splice variants have been shown to lack a ligand-binding domain (LBD), however, they exhibit higher AR transcriptional activity in CaP cells. ${ }^{12}$ The mechanisms through which functionally active AR splice variants (lacking LBD) arise during progression of disease are not well known. Using the rapid amplification of cDNA ends technique, Dehm et $\mathrm{al}^{13}$ reported that the splicing of a novel exon within AR intron 2 introduces a premature stop codon upstream of exon 3 in the AR transcript that would encode an AR protein (lacking the second zinc finger of the DNA-binding domain and LBD) if translated. Previously, it has been identified that up to seven different AR splice variants lack the LBD. ${ }^{14}$

Further, research has suggested that activation of splice variants of AR could be a possible mechanism involved in the growth of tumor cells and emergence of the CRPC phenotype in CaP patients post-androgen-ablation therapy. ${ }^{12-14}$ Among all identified AR splice variants, AR-V7, or AR3, has been detected in several human CaP cell line xenografts and normal and malignant human prostate-tissue samples. ${ }^{14}$ AR-V7 levels are generally higher in CRPC versus androgen-dependent tumors, and AR-V7 expression in early stage $\mathrm{CaP}$ has been associated with a worse prognosis after radical prostatectomy. ${ }^{14}$ The significance of AR splice variants in CRPC could be understood from the observation that these variants activate a subset of genes in prostatic tumor cells, which are not activated by full-length AR in the presence of androgens. ${ }^{14}$ An important finding in this context is a report by Sun et al showing that AR splice variants activate genes involved in the metabolism of androgens; this therefore suggests that expression of AR splice variants in tumor cells may provide a survival advantage in a low-androgen environment. $^{15}$

\section{The AR as therapeutic target in CRPC}

The AR has emerged as a promising therapeutic target for the treatment of both androgen-dependent $\mathrm{CaP}$ and CRPC, and several strategies to inhibit AR activation have been suggested. These include targeting the AR directly or inhibiting the resources/rate-limiting enzymatic pathways that lead to its activation in CRPC tumors. ${ }^{16}$ Several approaches to inhibiting AR expression and activity have been suggested. The classical approach leads to the identification of novel agents that inhibit AR expression or activity in CRPC cells. There is an enormous amount of literature regarding the efficacy of synthetic or natural agents in inhibiting AR expression, activity, or both under laboratory conditions (see Chi et $\mathrm{al}^{16}$ and Siddique et $\mathrm{al}^{17}$ and references therein these studies). However, the systemic toxicity, inability to achieve pharmacological doses, and low bioavailability does not permit most of these agents to be pursued beyond the laboratory stage, although some seem very promising. Recently, Siddique et $\mathrm{al}^{17}$ showed that lupeol, a small natural molecule exhibiting a structural similarity to cholesterol, significantly inhibits the activity of AR in CRPC cells and tumor xenografts. It is noteworthy that lupeol was observed to be highly stable under physiological conditions and exhibited high bioavailability in mice. ${ }^{17}$

Accumulating evidence suggests that targeting AR in the late stage of disease could be an ideal strategy, since the AR is highly amplified in this disease stage. In light of this, several agents are being pursued that could specifically 
target AR in CRPC at a late stage of disease. Among these, MDV-3100, a potent agent that specifically targets AR in CRPC cells, is in clinical trial and has shown promising results. $^{18}$

Further, AR knockdown has been suggested as a promising strategy based on the study in which knockdown of AR expression in CRPC cell lines was observed to inhibit cell proliferation. ${ }^{19}$ Several agents have been reported that were observed to decrease the expression of the AR under in vitro conditions (see Snoek et $\mathrm{al}^{19}$ and references therein) However, none of these agents have so far moved to the translational stage.

According to Ryan et al, ${ }^{20}$ a divergence of disease biology may occur in which certain patients develop CRPC disease that continues to rely to some extent on androgen-AR signaling and is thus amenable to therapies that target androgen synthesis or receptor activation. In CRPC tumor tissues, levels of dehydroepiandrosterone, dehydroepiandrosteronesulfate, and 5-androstenediol exceed the concentrations of testosterone and dihydrotestosterone and can activate wild-type and mutant AR. ${ }^{21}$ In addition, adrenal androgens can be metabolized and converted to dihydrotestosterone in $\mathrm{CaP}$ cells. ${ }^{21,22}$ These facts have led to the testing of agents that would indirectly inhibit activation of the AR in CRPC cells by blocking adrenal steroidogenesis with the aim of establishing this strategy as a therapy to treat CRPC. ${ }^{22}$ In this direction, the clinical efficacy of the antifungal agent ketoconazole (as a blocker of cytochrome P450-17 (CYP) and 11 b-hydroxylase, a rate-limiting enzyme responsible for mediating the conversion of cholesterol to androgens) has been extensively studied (see Hamada et $\mathrm{al}^{23}$ and references therein). Hamada et $\mathrm{a}^{23}$ showed that the presence of a polymorphism in the promoter region of the CYP17 gene is associated with survival in patients with CRPC, regardless of the therapy. In clinical settings, treatment with ketoconazole was observed to lead to a prostate-specific antigen (PSA) decline of $>50 \%$ in $46 \%-62 \%$ of CaP patients. ${ }^{24-26}$ Further, results of a randomized Phase III trial in men with CRPC demonstrated a PSA response of $50 \%$ or greater in $27 \%$ of patients treated with ketoconazole; however, no difference in overall survival was observed. ${ }^{24-26}$ It should be mentioned that ketoconazole is not a selective adrenal inhibitor and could lead to adrenal insufficiency.

Recently, a new class of drugs that inhibit AR activity by reducing the availability of androgenic steroids in CRPC patients has been discovered. ${ }^{27}$ Abiraterone acetate is a potent and selective inhibitor of CYP17 (17-hydroxylase/
C17, 20-lyase) enzyme. ${ }^{27}$ Abiraterone acetate is capable of reducing androgenic steroid production downstream from CYP17. Phase I and II studies have demonstrated the maximum tolerated dose and safety of abiraterone acetate. ${ }^{27,28}$ Moreover, the results of a recently conducted double-blind placebo-controlled Phase III study of abiraterone acetate and prednisone in chemotherapy-refractory metastatic CRPC patients are promising. ${ }^{27,28}$ The median overall survival for patients treated in the abiraterone/prednisone arm was 14.8 months compared with 10.9 months for the patients in the prednisone/placebo arm (hazard ratio 0.646, $P<0.0001)$. This benefit was observed across all patients, regardless of sites of metastatic disease and number of prior chemotherapy regimens undertaken. It is noteworthy that the abiraterone acetate treatment caused a significant delay in the radiographic progression-free survival in CRPC patients. ${ }^{29}$

\section{Phosphoinositide-3-kinase (PI3K) and Akt in CRPC disease Role in emergence of disease}

Clinical observations suggest that the loss of AR expression may serve as an alternative means of escaping androgen withdrawal or AR-targeted therapies, possibly through concomitant activation of compensatory signaling pathways. One of the possible survival and proliferative pathways is the PI3K/Akt signaling pathway, which is negatively regulated by the phosphatase and tensin homolog (PTEN) tumor suppressor. ${ }^{30}$ The PI3K/AKT pathway plays critical roles in mammalian cell survival signaling and is activated in various cancers including $\mathrm{CaP}$. Morgan et $\mathrm{al}^{31}$ reported that PI3K/Akt signaling is upregulated in $30 \%-50 \%$ of $\mathrm{CaP}$ cases and associated this activation of signaling with the loss of PTEN function. PTEN function loss occurs frequently during human $\mathrm{CaP}$ progression, with up to $70 \%$ of late stage samples exhibiting loss of PTEN function or activation of the PI3K pathway. ${ }^{32,33}$ Alterations in PTEN expression are associated with a number of clinico-pathologic variables in $\mathrm{CaP}$. It has been determined that loss of PTEN expression correlates with Gleason score and pathologic stage of primary tumors and increases the incidence of development of lymph node metastases. ${ }^{32,33}$ Further, PTEN function loss or activation of the PI3K/AKT pathway has been shown to enhance CRPC disease development; ${ }^{32-35}$ conversely, restoration of functional PTEN activity has been shown to block the growth of PTEN-negative prostate tumors in a xenograft mouse model and restore sensitivity to chemotherapy 
(see Carrión-Salip et al, ${ }^{32}$ Krohn et al, ${ }^{33}$ Li et al, ${ }^{34}$ and Mulholland et $\mathrm{al}^{35}$ and references therein).

PTEN function loss causes the activation of the PI3K/ AKT pathway, resulting in the phosphorylation of the Akt molecule. Phosphorylation of Akt has been used as a surrogate biomarker for studying this pathway. Phospho-Akt levels have been shown to be significantly higher in highgrade prostate tumors than in low- or intermediate-grade tumors. Study by Bedolla et $\mathrm{al}^{36}$ showed that PTEN in combination with phospho-Akt (an activated form of Akt protein), is a better predictor of the risk of recurrence of disease in $\mathrm{CaP}$ patients. In this study, $90 \%$ of all cases with high phospho-Akt and negative PTEN were recurrent, whereas $88.2 \%$ of those with low phospho-Akt and positive PTEN were nonrecurrent. ${ }^{36}$

Activation of the PI3K/Akt pathway has been associated with ligand-independent activation of the AR and with progression of CRPC phenotype. In addition to promoting cell survival and inhibiting apoptosis, the Akt pathway is reported to regulate cell growth, proliferation, and angiogenesis through the mammalian target of rapamycin (mTOR) pathway, thus activating proproliferation genes such as $c-M y c$, cyclin D, nuclear factor kappa B, and vascular endothelial growth factor. ${ }^{37}$ Activated Akt is reported to phosphorylate the FoxO subfamily of forkhead box family transcription factors, which inhibits transcription of several pro-apoptotic genes, for example, Fas-L, IGFBP1, and Bim. ${ }^{38-40}$ In addition, Akt is reported to modulate cell-cycle progression through its inhibitory phosphorylation of the cyclin-dependent kinase inhibitors, p2 $1^{\mathrm{WAF} 1 / \mathrm{CIP} 1}$ and $\mathrm{p} 27^{\mathrm{KIP} 1}$ (see Kharaziha et $\mathrm{al}^{41}$ and Leong et $\mathrm{al}^{42}$ ) and stabilizing the expression levels of proproliferative protein cyclin D1.43,44

\section{The PI3K/AKT pathway as a target for CRPC}

Kreisberg et a ${ }^{45}$ conducted a comparative study on Akt activation and established the significance of the Akt pathway in therapy failure in $\mathrm{CaP}$ patients. The study reported a significant increase in mean phospho-Akt staining $(P<0.001)$ in the PSA failures versus non-failures: $222.18 \pm 33.9(\mathrm{n}=37)$ versus $108.79 \pm 104.57(\mathrm{n}=16)$. Using the best-fitting multiple logistic regression equation, a 100-point increase in activated Akt (phospho-Akt) levels resulted in a $160 \%$ increase in the odds of being a PSA failure. Further, Kaarbø et $\mathrm{al}^{46}$ showed that the PI3K pathway is dominant over AR signaling in $\mathrm{CaP}$ cells and should be considered in developing novel therapeutic strategies for $\mathrm{CaP}$. The rationale for targeting the PI3K/Akt pathway in combination therapy comes from data describing constitutive or residual pathway activation in tumor cells that have developed resistance to conventional chemotherapy and radiation (see Kreisberg et $\mathrm{al}^{45}$ and Kaarbø et $\mathrm{al}^{46}$ and references therein).

Under preclinical conditions, inhibitors of PI3K such as LY294002 and wortmannin diminish signaling to Akt. ${ }^{47,48}$ Although these commercially available inhibitors effectively inhibit PI3K, poor solubility and high toxicity have limited their clinical applications. However, these compounds provide powerful preclinical tools to study the cellular consequences of pathway inhibition.

Perifosine, a lipid-based compound, has been reported to act as a potent inhibitor of Akt and in preclinical settings it inhibits the growth of $\mathrm{CaP}$ cells along with Akt activity. ${ }^{49}$ Results of a Phase II clinical study conducted with recurrent $\mathrm{CaP}$ patients showed that, although well tolerated, perifosine did not meet prespecified PSA criteria for response as a single agent. ${ }^{50}$ However, $20 \%$ of patients had evidence of PSA reduction, suggesting modest single-agent clinical activity. This study suggested that effects of perifosine in combination with androgen deprivation or chemotherapy could show better results than monotherapy in $\mathrm{CaP}$ patients.

One downstream target of the PI3k/Akt pathway is the mTOR kinase, which is activated in PTEN-negative tumors. ${ }^{51}$ Preclinical studies suggested that targeting mTOR could reverse the growth-promoting effects of the PI3K/ Akt pathway in CaP cells (see Majumder et $\mathrm{al}^{51}$ and references therein). Several agents (such as everolimus and deforolimus) directed at $\mathrm{Akt} / \mathrm{mTor}$ pathways have been developed and are in preclinical and clinical trials to treat $\mathrm{CaP}$. Several in vitro and in vivo studies conducted with transgenic mice expressing human Akt have shown that prostate tumor development could be inhibited with the treatment of everolimus, an oral mTOR inhibitor. ${ }^{51}$ With these promising results at preclinical stage, everolimus as a therapeutic agent has moved to Phase I and II clinical trials. The results of a pharmacodynamic study conducted in $\mathrm{CaP}$ patients suggested that mTOR inhibition due to everolimus intake could be detected in prostate tumor tissues. ${ }^{52,53}$ Further, everolimus was tested in combination with docetaxel in a Phase I study using fluorodeoxyglucose positron emission tomography imaging as a pharmacodynamic endpoint. ${ }^{54}$ The combination was found to be tolerable (everolimus $10 \mathrm{mg}$ daily + docetaxel $70 \mathrm{mg} / \mathrm{m}^{2}$ every 3 weeks) caused a decrease in fluorodeoxyglucose-avidity PSA levels. ${ }^{54}$ Although mTOR inhibitors have little single-agent activity in advanced CRPC, the combination of these agents with 
docetaxel is an attractive option given their ability to reverse chemotherapy resistance in $\mathrm{CaP}$ cell lines.

\section{Janus kinase (JAK)/signal transducer and activator of transcription (STAT) 3 and CRPC}

\section{Role in pathogenesis of disease}

STAT3, a component of the JAK/STAT signaling pathway, can be activated by tyrosine phosphorylation as p-STAT3 and is involved in the regulation of cellular growth, survival, and oncogenesis. ${ }^{55}$ The JAK/STAT pathway is activated constitutively in CaP cells. ${ }^{56}$ The significance of STAT3 in the emergence of CRPC disease was ascertained from a report showing that levels of activated STAT3 are significantly higher in AR-negative prostate tumor cells (Du145 and PC3) than in AR positive. ${ }^{56}$ STAT3 is stimulated by cytokines, particularly interleukin-6 (IL-6). ${ }^{57}$ The signal transduction of IL-6 involves the activation of JAK tyrosine kinase family members, thus resulting in the activation of STAT3. Studies by $C$ hen et $\mathrm{al}^{57}$ and Lou et $\mathrm{l}^{58}$ have shown that IL-6-induced AR activity requires the activation of STAT3 that ultimately influences survival, proliferation, apoptosis, angiogenesis, and invasive potential of prostatic tumor cells. Constitutively active STAT3 is reported to increase motility of prostate epithelial cells and promote prostate tumorigenesis.

A study conducted with prostatic tissue biopsies from 52 patients with localized $\mathrm{CaP}$ and 80 patients free of $\mathrm{CaP}$ showed that $\mathrm{p}$-STAT3 could be utilized to detect $\mathrm{CaP}$ with initial negative biopsies. ${ }^{55}$ This study suggested that p-STAT3 could be a potential adjunctive tool for a current $\mathrm{CaP}$ diagnostic program and developed as a diagnostic biomarker that can predict the onset of $\mathrm{CaP}$ up to 40 months earlier than currently used diagnostic approaches. ${ }^{55}$ Liu et $\mathrm{al}^{59}$ reported that levels of p-JAK-1(Tyr1022/1023) and p-STAT-3(Tyr705) are positively correlated with Gleason score and clinical stage of patients with CaP. Importantly, $\mathrm{CaP}$ patients exhibiting lower p-STAT and p-JAK levels exhibited increased recurrence-free survival rates. ${ }^{59}$ Moreover, for patients treated by definitive or hormonal therapy, the recurrence-free survival rates in those with lower p-JAK-1 $(P<0.001$ and 0.012 , respectively) and p-STAT-3(Tyr705) expression $(P<0.001$ and 0.015 , respectively) were significantly higher than in those with higher expression. ${ }^{59}$ This study showed that p-JAK-1(Tyr1022/1023) and p-STAT-3(Tyr705) levels in needlebiopsy specimens are prognostic factors for $\mathrm{CaP}^{59}$ The JAK/ STAT3 pathway has been reported to be induced by elevated levels of circulating IL-6 in the serum of patients, which in turn results in the activation of AR activity. ${ }^{60,61}$

\section{The JAK/STAT pathway as a target for CRPC}

Growing evidence has shown that the STAT3 could be an effective molecular target for CRPC therapy. ${ }^{62} \mathrm{~A}$ report from the National Institutes of Health Molecular Libraries Program has suggested that the identification of novel compounds that selectively inhibit STAT3 activity may lead to useful tools to reduce cell proliferation, inflammation, and chemotherapeutic resistance. ${ }^{63}$ Blockade of STAT3 expression is reported to suppress proliferation of $\mathrm{CaP}$ cells in vitro and prostate tumorigenicity in vivo.

Keeping in view the significance of STAT3 as a potential target for therapy, various inhibitors have been developed to target various molecular steps in the STAT3 activation pathway. ${ }^{63,64}$ The potential STAT3 inhibitors include ML116, tyrphostin AG490, ursolic acid, cucurbitacin I, sanguinarine, antisense and decoy oligonucleotides, dominant negative STAT3 protein, and various small molecule inhibitors. ${ }^{41,64-67}$ Kim et $\mathrm{al}^{66}$ showed that an extract of Chrysanthemum indicum containing bioactive compounds such as sudachitin, hesperetin, chrysoeriol, and acacetin suppressed constitutive STAT3 and JAK1/2 activation, and induced apoptosis in CRPC cells. Further, Kwon et al ${ }^{67}$ reported that piceatannol, a polyphenol detected in grapes and red wine, inhibits the invasive potential of $\mathrm{CaP}$ cells by decreasing IL-6/ STAT3 signaling and Kharaziha et $\mathrm{al}^{41}$ reported the suppression of STAT3 by sorafenib in CRPC cells. This study showed that the combination of sorafenib with Bcl-2 antagonists (ABT737) might constitute a promising therapeutic strategy against CRPC. ${ }^{41}$

\section{Notch and CRPC Relevance of notch in CaP}

The notch signaling pathway comprises receptors, ligands, transcriptional complex components in the nucleus, and downstream genes, which are widely conserved..$^{42}$ Notch signaling is mediated by its receptors and ligands. ${ }^{42,68}$ Four notch receptors, NOTCH-1, $-2,-3$, and -4 , and at least five notch ligands, Jagged-1, Jagged-2, Delta-1, Delta-3, and Delta-4, have been identified in humans. ${ }^{42,68}$ Notch receptors interact with their ligands and undergo a series of proteolytic cleavages by the presenilin complex that is essential gamma-secretase activity. This results in the generation of an intracellular domain, which acts as a transcriptional co-activator (see Leong et a ${ }^{42}$ and Rizzo et $\mathrm{al}^{68}$ and references therein). The notch signaling pathway 
is reported to play important roles in several biological processes, including embryonic development, adult tissue homeostasis, and tumorigenesis. ${ }^{42,68}$ Recent studies have established an association between aberrant notch signaling and the development of several tumor types. ${ }^{42,68}$

Notch signaling is reported to be required for normal prostate development; however, its role in $\mathrm{CaP}$ development is not fully understood due to conflicting reports. ${ }^{69,70}$ Belandia et $\mathrm{al}^{71}$ showed that NOTCH-1 signaling represses AR signaling and regulates prostate tumor cell motility. While some studies, such as that of Shou et $\mathrm{al}^{72}$ have reported that notch signaling acts as a tumor-suppressing pathway in CaP cells, the majority of studies have reported the tumor-promoting role of notch in $\mathrm{CaP}$ cells. However, this conflict could be linked to the consequences of aberrant notch signaling, which in turn depends on cell context, dose, and timing. Martin et $\mathrm{al}^{73}$ showed that the notch ligand Jagged-1 is regulated by androgens in CaP cells. Using CRPC cells (Du145 and 22Rn1) and human prostate tumor specimens, Whelan et al showed that loss of NOTCH-1 signaling promotes prostate tumor development through its role as a regulator of the PTEN tumor suppressor gene. ${ }^{74}$ Reports suggest that the notch ligand Jagged-1 is highly expressed in prostatic tumor cells in human $\mathrm{CaP}$ patients who have disease recurrence after radical prostatectomy. ${ }^{74}$ Santagata et $\mathrm{al}^{75}$ reported an association between the activated notch signaling and recurrence of disease as CRPC phenotype in human $\mathrm{CaP}$ patients. A growing body of evidence suggests that neuroendocrine differentiation of prostatic tumors plays a role in the development of CRPC.

\section{The notch pathway as a target for CRPC}

Since elevated notch activity has been shown to be a contributing factor along with perturbations in other critical signaling pathways in several cancer types, a growing consensus among researchers is that therapeutic inhibition of notch signaling could be widely applicable, either alone or in combination with other chemotherapeutic approaches. ${ }^{76}$ The utilization of notch as a target for cancer therapy could be considerably prudent, depending on extremely rigorous preclinical studies in specific tumor types. Several studies have provided evidence about the utility of notch signaling as a therapeutic target in CaP cells. ${ }^{77,78}$ Studies by Wang et $\mathrm{al}^{77}$ and Bin Hafeez et $\mathrm{al}^{78}$ have shown that targeting downregulation of NOTCH-1 and its receptor results in the inhibition of $\mathrm{CaP}$ cell growth, migration, and invasion. Further, Whelan et al demonstrated that reactivation of NOTCH-1 could inhibit the invasive potential of CRPC cells. ${ }^{74}$ The emerging complexity of notch in $\mathrm{CaP}$ can be ascertained from the report showing that targeted downregulation of NOTCH-1 has been shown to inhibit growth of metastatic PC-3 cells. ${ }^{78}$

It has been suggested that the targeting of distinct growth factor pathways may be effective for eradicating $\mathrm{CaP}$ cells with stem cell-like features, thus improving the efficacy of current antihormonal treatments and chemotherapies. ${ }^{79}$ Therefore, the targeting of molecules that either regulate or mediate notch signaling is being suggested as an ideal strategy. ${ }^{79}$ Kong et al have shown that notch signaling is regulated by micro-RNA-200 in CaP cells. ${ }^{79}$ This study showed that reactivating miR-200 causes a reduction in NOTCH-1 activity, thus inhibits the prostatosphere-forming ability of CaP cells. ${ }^{79}$ Ligand-dependent activation of notch requires cleavage by gamma-secretase complex (see Stein et $\mathrm{al}^{80}$ and references therein). Gamma-secretase inhibitors have been tested for their anticancer potential in preclinical and clinical trials for various cancer types. ${ }^{80}$ Recent studies have shown that several natural compounds mimic gamma-secretase inhibitors and thereby inhibit CRPC cell growth by inhibiting gamma-secretase (see Kim et $\mathrm{al}^{81}$ and references therein). Whether targeting gamma-secretase would be beneficial in CRPC patients is not yet clear due to the conflicting studies regarding role of notch in $\mathrm{CaP}$. At present, a National Cancer Institute-sponsored clinical trial (Phase II) is underway to test gamma-secretase inhibitor RO4929097 alone and in combination with bicalutamide for treating $\mathrm{CaP}$ patients who previously underwent definitive local therapy for prostatic adenocarcinoma in humans. ${ }^{80,82}$ The primary results of this randomized Phase II study show that bicalutamide decreased PSA by more than 50\% in 12/16 patients and RO4929097 was well tolerated. ${ }^{80}$

\section{The immune system and CRPC Rationale for immunotherapy}

Immunotherapy is a form of biological therapy that exploits the immune system to delay or inhibit malignant growth either by targeting tumor-associated antigens or by disrupting molecular pathways that promote tumor growth. A better understanding of the role of immune activation in $\mathrm{CaP}$ and the availability of prostate tissue-specific tumor antigens has facilitated the development of several immune-based therapeutic approaches. These approaches either involve therapeutic cancer vaccines designed to elicit antitumor $\mathrm{T}$ cell responses or monoclonal antibody drugs with intrinsic immunologic properties. The rationale for immunotherapy in $\mathrm{CaP}$ is based on several observations, including: presence of several altered self-antigens, 
glycoproteins, and glycolipids, which are overexpressed on $\mathrm{CaP}$ cells; a long history of disease/disease burden, which could be amenable to treatment; and intrinsic low proliferative index of most chemoresistant prostatic tumors (see Vieweg ${ }^{83}$ and references therein). In addition, multiple clinical trials have demonstrated that the majority of $\mathrm{CaP}$ patients can mount a vigorous antitumor response despite their disease status. ${ }^{83}$ It is noteworthy that active or passive immunotherapy does not rely on high cell proliferation, and can be directed against any gene product expressed by $\mathrm{CaP}$ cells. Further, because $\mathrm{CaP}$ is commonly a slowly progressing disease, multiple vaccinations or boosting is possible, thereby allowing sufficient time to develop a potent antitumor response. Recent studies have shown that there is considerable synergy between cancer vaccination and hormonal ablative therapy, which, in combination, boosts the expansion of vaccine-induced effector cells. ${ }^{83-85}$ Therefore, active immunotherapy against $\mathrm{CaP}$ may be most efficacious when administered after androgen ablation. ${ }^{83}$

\section{The immune system as a target for CRPC therapy}

For CRPC patients, a variety of monoclonal antibody-based approaches are currently in development. A widely used approach is the utility of unconjugated antibodies that target and kill cancer cells by either enhancing complement fixation or initiating antibody-dependent cell-mediated cytotoxicity. Several surface proteins have been tested as markers and targets for immunotherapy in CaP disease (see Moffatt et al ${ }^{86}$ and references therein). These include mucins MUC-1, -2 , Globo H, prostate stem-cell antigen, PSA, and prostatespecific membrane antigen. ${ }^{87,88}$ Granulocyte-macrophage colony-stimulating factor (GM-CSF) is a small secreted cytokine that binds to specific cell-surface receptors and activates phagocytic macrophages and antigen-presenting dendritic cells. ${ }^{87}$ The therapeutic effect of recombinant GM-CSF as an anticancer agent has been studied in several models. Published studies have reported that autologous or allogeneic prostate tumor cells transfected to produce GM-CSF, demonstrating the generation of immune response (see Zhang et $\mathrm{al}^{87}$ and van den Eertwegh et $\mathrm{al}^{88}$ and references therein). Recently, antibodies such as MDX-010 (ipilimumab) that block human cytotoxic $\mathrm{T}$ lymphocyte-associated protein 4 have entered human Phase I and II clinical trials in $\mathrm{CaP}$ patients ${ }^{84}$ In clinical settings, MDX-010 has been tested in several $\mathrm{CaP}$ patients, either as monotherapy or in combination with chemotherapy and vaccines. All these studies revealed that intravenous administration of MDX-010 is safe and elicits clinical activity (see Thakur et $\mathrm{al}^{89}$ and Drake and Antonarakis $^{90}$ and references therein).

Several cancer vaccines are being tested in clinical trials for their efficacy in treating CRPC. These include sipuleucel-T, DCVax ${ }^{\circledR}$ (Northwest Biotherapeutics, Bethesda, MD), GVAX (BioSante Pharmaceuticals Inc., IL), and PROSTVAC $^{\circledR}$ (Bavarian Nordic, Kvistgaard, Denmark). Sipuleucel-T is a cellular immunotherapy product that consists of an enriched population of a patient's peripheral blood mononuclear cells, which are exposed in vitro to a fusion protein comprised of GM-CSF and prostatic acid phosphatase. ${ }^{90,91}$ These peripheral blood mononuclear cells, which include a large proportion of antigen-presenting cells, are then infused back into the patient to stimulate antitumor T-cell responses..$^{90,91}$ Three Phase III sipuleucel-T trials enrolled CRPC patients and reported an increase of 4.1-4.3 months in median overall survival compared with placebo. Estimated survival at 36 months was $32 \%-33 \%$ in the active arms versus $15 \%-23 \%$ in the placebo arms..$^{90,91}$ However, early results of combination therapy with docetaxel have not demonstrated benefits of sipuleucel-T use following chemotherapy ${ }^{90,91}$ DCVax prostate vaccine consists of autologous, monocyte-derived dendritic cells loaded with a recombinant prostate-specific membrane antigen and has recently advanced to Phase III clinical testing in $\mathrm{CaP}$ patients. ${ }^{92} \mathrm{GVAX}$ vaccine is composed of allogeneic $\mathrm{CaP}$ cells genetically engineered to secrete GM-CSF. ${ }^{93}$ PROSTVAC vaccine consists of a recombinant vaccinia viral expression cassette engineered to contain a copy of the human PSA and surface receptors such as intercellular adhesion molecules.

\section{Conclusion}

$\mathrm{CaP}$ is a heterogeneous disease with a number of different genetic/pathophysiologic clusters. Future directions to treat CRPC patients will include custom tailoring of therapies designed on the basis of specific molecules or molecular signatures expressed by tumors that could be used as potential targets for therapeutic agents. The utilization of gene array technology (to gather information about the genes driving the growth of tumor of a selected patient) is expected to play a big role in future CRPC therapies. ${ }^{83}$ Currently, neither a method for determining the homogeneous versus heterogeneous nature of tumor nor a method for the prevention of the development of CRPC phenotype from dependent androgen-dependent $\mathrm{CaP}$ cells is available; therefore, these should be critical areas for extensive future study. ${ }^{94}$ In addition, newer agents are needed to target the 
more than $95 \%$ of $\mathrm{CaP}$ cells within a given metastatic site that are not immediately proliferating.

\section{Disclosure}

The authors declare no conflicts of interest in this work.

\section{References}

1. Kim W, Ryan CJ. Androgen receptor directed therapies in castrationresistant metastatic prostate cancer. Curr Treat Options Oncol. 2012;13(2):189-200.

2. Bluemn EG, Nelson PS. The androgen/androgen receptor axis in prostate cancer. Curr Opin Oncol. 2012;24(3):251-257.

3. Green SM, Mostaghel EA, Nelson PS. Androgen action and metabolism in prostate cancer. Mol Cell Endocrinol. 2012. Epub Mar 20.

4. Shiota M, Yokomizo A, Naito S. Increased androgen receptor transcription: a cause of castration-resistant prostate cancer and a possible therapeutic target. $J$ Mol Endocrinol. 2011;47(1):R25-R41.

5. Feldman BJ, Feldman, D. The development of androgen-independent prostate cancer. Nat Rev Cancer 2001;1(1):34-45.

6. Nadiminty N, Gao AC. Mechanisms of persistent activation of the androgen receptor in CRPC: recent advances and future perspectives. World J Urol. 2012;30(3):287-295.

7. Golias Ch, Iliadis I, Peschos D, Charalabopoulos K. Amplification and co-regulators of androgen receptor gene in prostate cancer. Exp Oncol. 2009;31(1):3-8.

8. Gregory CW, He B, Johnson RT, et al. A mechanism for androgen receptor-mediated prostate cancer recurrence after androgen deprivation therapy. Cancer Res. 2001;61(11):4315-4319.

9. Agoulnik IU, Weigel NL. Androgen receptor action in hormone-dependent and recurrent prostate cancer. J Cell Biochem. 2006;99(2): 362-372.

10. Cai C, Chen S, Ng P, et al. Intratumoral de novo steroid synthesis activates androgen receptor in castration-resistant prostate cancer and is upregulated by treatment with CYP17A1 inhibitors. Cancer Res. 2011;71(20):6503-6513.

11. Li Y, Hwang TH, Oseth LA, et al. AR intragenic deletions linked to androgen receptor splice variant expression and activity in models of prostate cancer progression. Oncogene. 2012. Epub Jan 23.

12. Dehm SM, Tindall DJ. Alternatively spliced androgen receptor variants. Endocr Relat Cancer. 2011;18(5):R183-R196.

13. Dehm SM, Schmidt LJ, Heemers HV, Vessella RL, Tindall DJ. Splicing of a novel androgen receptor exon generates a constitutively active androgen receptor that mediates prostate cancer therapy resistance. Cancer Res. 2008;68(13):5469-5477.

14. Watson PA, Chen YF, Balbas MD, et al. Constitutively active androgen receptor splice variants expressed in castration-resistant prostate cancer require full-length androgen receptor. Proc Natl Acad Sci USA. 2010;107(39):16759-16765.

15. Sun S, Sprenger CC, Vessella RL, et al. Castration resistance in human prostate cancer is conferred by a frequently occurring androgen receptor splice variant. $J$ Clin Invest. 2010;120(8):2715-2730.

16. Chi KN, Bjartell A, Dearnaley D, et al. Castration resistant prostate cancer: from new pathophysiology to new treatment targets. Eur Urol. 2009;56(4):594-605.

17. Siddique HR, Mishra SK, Karnes RJ, Saleem M. Lupeol, a novel androgen receptor inhibitor: implications in prostate cancer therapy. Clin Cancer Res. 2011;17(16):5379-5391.

18. Tran C, Ouk S, Clegg NJ, et al. Development of a second-generation antiandrogen for treatment of advanced prostate cancer. Science. 2009;324(5928):787-790.

19. Snoek R, Cheng H, Margiotti K, et al. In vivo knockdown of the androgen receptor results in growth inhibition and regression of wellestablished, castration-resistant prostate tumors. Clin Cancer Res. 2009;15(1):39-47.
20. Ryan CJ, Tindall DJ. Androgen receptor rediscovered: the new biology and targeting the androgen receptor therapeutically. J Clin Oncol. 2011;29(27):3651-3658.

21. Koreckij TD, Trauger RJ, Montgomery RB, et al. HE3235 inhibits growth of castration-resistant prostate cancer. Neoplasia. 2009;11(11): 1216-1225.

22. Sharifi N. New agents and strategies for the hormonal treatment of castration-resistant prostate cancer. Expert Opin Investig Drugs. 2010;19(7):837-846.

23. Hamada A, Danesi R, Price DK, et al. Association of a CYP17 polymorphism with overall survival in Caucasian patients with androgenindependent prostate cancer. Urology. 2007;70(2):217-220.

24. Keisner SV, Shah SR, Jean GW, Ussery SM, Dowell JE. Retrospective analysis of the consequences of acid suppressive therapy on ketoconazole efficacy in advanced castration-resistant prostate cancer. Ann Pharmacother. 2010;44(10):1538-1544.

25. Ngo LS, Yeo A, Wong AS, Tay MH. Efficacy of low-dose ketoconazole in hormone refractory prostate cancer patients at the National Cancer Centre and The Cancer Institute, Singapore. Ann Acad Med Singapore. 2007;36(10):811-814.

26. Nakabayashi M, Oh WK, Jacobus S, et al. Activity of ketoconazole after taxane-based chemotherapy in castration-resistant prostate cancer. BJU Int. 2010;105(10):1392-1396.

27. Danila DC, Morris MJ, de Bono JS, et al. Phase II multicenter study of abiraterone acetate plus prednisone therapy in patients with docetaxel-treated castration-resistant prostate cancer. J Clin Oncol. 2010;28(9):1496-1501.

28. Ryan CJ, Smith MR, Fong L, et al. Phase I clinical trial of the CYP17 inhibitor abiraterone acetate demonstrating clinical activity in patients with castration-resistant prostate cancer who received prior ketoconazole therapy. J Clin Oncol. 2010;28(9):1481-1488.

29. Yang LP. Abiraterone acetate: in metastatic castration-resistant prostate cancer. Drugs. 2011:71(15):2067-2077.

30. Bartholomeusz C, Gonzalez-Angulo AM. Targeting the PI3K signaling pathway in cancer therapy. Expert Opin Ther Targets. 2012;16(1): $121-130$.

31. Morgan TM, Koreckij TD, Corey E. Targeted therapy for advanced prostate cancer: inhibition of the PI3K/Akt/mTOR pathway. Curr Cancer Drug Targets. 2009;9(2):237-249.

32. Carrión-Salip D, Panosa C, Menendez JA, et al. Androgen-independent prostate cancer cells circumvent EGFR inhibition by overexpression of alternative HER receptors and ligands. Int J Oncol. 2012. Epub Jun 6.

33. Krohn A, Diedler T, Burkhardt L, et al. Genomic Deletion of PTEN Is Associated with Tumor Progression and Early PSA Recurrence in ERG Fusion-Positive and Fusion-Negative Prostate Cancer. Am J Pathol. 2012. Epub Jun 13.

34. Li Y, Su J, DingZhang X, et al. PTEN deletion and heme oxygenase-1 overexpression cooperate in prostate cancer progression and are associated with adverse clinical outcome. J Pathol. 2011;224(1):90-100.

35. Mulholland DJ, Tran LM, Li Y, et al. Cell autonomous role of PTEN in regulating castration-resistant prostate cancer growth. Cancer Cell. 2011;19(6):792-804.

36. Bedolla R, Prihoda TJ, Kreisberg JI, et al. Determining risk of biochemical recurrence in prostate cancer by immunohistochemical detection of PTEN expression and Akt activation. Clin Cancer Res. 2007;13(13):3860-3867.

37. Ghosh PM, Malik S, Bedolla R, Kreisberg JI. Akt in prostate cancer: possible role in androgen-independence. Curr Drug Metab. 2003;4(6):487-496.

38. Datta SR, Dudek H, Tao X, et al. Akt phosphorylation of BAD couples survival signals to the cell-intrinsic death machinery. Cell. 1997;91(2):231-241.

39. Nicholson KM, Anderson NG. The protein kinase B/Akt signalling pathway in human malignancy. Cell Signal. 2002;14(5):381-395.

40. Romashkova JA, Makarov SS. NF-kappaB is a target of AKT in antiapoptotic PDGF signalling. Nature. 1999;401(6748):86-90. 
41. Kharaziha P, Rodriguez P, Li Q, et al. Targeting of distinct signaling cascades and cancer-associated fibroblasts define the efficacy of Sorafenib against prostate cancer cells. Cell Death Dis. 2012;3:e262.

42. Leong KG, Karsan A. Recent insights into the role of Notch signaling in tumorigenesis. Blood. 2006;107(6):2223-2233.

43. Shin I, Yakes FM, Rojo F, et al. PKB/Akt mediates cell-cycle progression by phosphorylation of $\mathrm{p} 27$ (Kip1) at threonine 157 and modulation of its cellular localization. Nat Med. 2002;8(10):1145-1152.

44. Diehl JA, Cheng M, Roussel MF, Sherr CJ. Glycogen synthase kinase3 beta regulates cyclin D1 proteolysis and subcellular localization. Genes Dev. 1998;12(22):3499-3511.

45. Kreisberg JI, Malik SN, Prihoda TJ, et al. Phosphorylation of Akt (Ser473) is an excellent predictor of poor clinical outcome in prostate cancer. Cancer Res. 2004;64(15):5232-5236.

46. Kaarbø M, Mikkelsen OL, Malerød L, et al. PI3K-AKT-mTOR pathway is dominant over androgen receptor signaling in prostate cancer cells. Cell Oncol. 2010;32(1-2):11-27.

47. Poh TW, Pervaiz S. LY294002 and LY303511 sensitize tumor cells to drug-induced apoptosis via intracellular hydrogen peroxide production independent of the phosphoinositide 3-kinase-Akt pathway. Cancer Res. 2005;65(14):6264-6274.

48. Seol JW, Lee YJ, Kang HS, et al. Wortmannin elevates tumor necrosis factor-related apoptosis-inducing ligand sensitivity in $\mathrm{LNCaP}$ cells through down-regulation of IAP-2 protein. Exp Oncol. 2005;27(2): $120-124$

49. Posadas EM, Gulley J, Arlen PM, et al. A phase II study of perifosine in androgen independent prostate cancer. Cancer Biol Ther. 2005;4(10): 1133-1137.

50. Chee KG, Longmate J, Quinn DI, et al. The AKT inhibitor perifosine in biochemically recurrent prostate cancer: a phase II California/Pittsburgh cancer consortium trial. Clin Genitourin Cancer. 2007;5(7):433-437.

51. Majumder PK, Febbo PG, Bikoff R, et al. mTOR inhibition reverses Aktdependent prostate intraepithelial neoplasia through regulation of apoptotic and HIF-1-dependent pathways. Nat Med. 2004;10(6):594-601.

52. Lerut E, Roskams T, Goossens E, et al. Molecular pharmacodynamic (MPD) evaluation of dose and schedule of RAD001 (everolimus) in patients with operable prostate carcinoma (PC). J Clin Oncol. 2005;23(16S):3071.

53. George DA, Armstrong AJ, Creel P, et al. A phase II study of RAD001 in men with hormone-refractory metastatic prostate cancer. Proc Genitourin Cancers Symp. 2008:Abstract 181.

54. Ross RW, Manola J, Oh WK, et al. Phase I trial of RAD001 (R) and docetaxel (D) in castration resistant prostate cancer (CRPC) with FDG-PET assessment of RAD001 activity. J Clin Oncol. 2008;26(Supp1): Abstract 5069.

55. Han G, Yu JY, Chen YD, et al. The usefulness of phosphorylated-signal transduction and activators of transcription 3 in detecting prostate cancer from negative biopsies. Eur J Surg Oncol. 2012;38(4):367-373.

56. Mora LB, Buettner R, Seigne J, et al. Constitutive activation of Stat3 in human prostate tumors and cell lines: direct inhibition of Stat3 signaling induces apoptosis of prostate cancer cells. Cancer Res. 2002;62(22):6659-6666

57. Chen T, Wang LH, Farrar WL. Interleukin 6 activates androgen receptor-mediated gene expression through a signal transducer and activator of transcription 3-dependent pathway in $\mathrm{LNCaP}$ prostate cancer cells. Cancer Res. 2000;60(8):2132-2135.

58. Lou W, Ni ZY, Dyer K, Tweardy DJ, Gao AC. Interleukin-6 induces prostate cancer cell growth accompanied by activation of stat 3 signaling pathway. Prostate. 2000;42(3):239-242.

59. Liu X, He Z, Li CH, Huang G, Ding C, Liu H. Correlation analysis of JAK-STAT pathway components on prognosis of patients with prostate cancer. Pathol Oncol Res. 2012;18(1):17-23.

60. Fearon KC, McMillan DC, Preston T, Winstanley FP, Cruickshank AM, Shenkin A. Elevated circulating interleukin-6 is associated with an acute-phase response but reduced fixed hepatic protein synthesis in patients with cancer. Ann Surg. 1991;213(1):26-31.
61. Drachenberg DE, Elgamal AA, Rowbotham R, Peterson M, Murphy GP. Circulating levels of interleukin-6 in patients with hormone refractory prostate cancer. Prostate. 1999;41(2):127-133.

62. He M, Young CY. New approaches to target the androgen receptor and STAT3 for prostate cancer treatments. Mini Rev Med Chem. 2009;9(3):395-400.

63. Madoux F, Koenig M, Sessions H, et al. Modulators of STAT Transcription Factors for the Targeted Therapy of Cancer (STAT3 Inhibitors). In: National Center for Biotechnology Information (US). Probe Reports from the NIH Molecular Libraries Program [book on the Internet]. Bethesda, MD: National Center for Biotechnology Information; August 28, 2009 [updated March 25, 2011]. Available from: http:// www.ncbi.nlm.nih.gov/books/NBK56232/. Accessed July 17, 2012.

64. Sun M, Liu C, Nadiminty N, Lou W, et al. Inhibition of Stat3 activation by sanguinarine suppresses prostate cancer cell growth and invasion. Prostate. 2012;72(1):82-89.

65. Shanmugam MK, Rajendran P, Li F, et al. Ursolic acid inhibits multiple cell survival pathways leading to suppression of growth of prostate cancer xenograft in nude mice. J Mol Med (Berl). 2011;89(7):713-727.

66. Kim C, Kim MC, Kim SM, et al. Chrysanthemum indicum L. Extract Induces Apoptosis through Suppression of Constitutive STAT3Activation in Human Prostate Cancer DU145 Cells. Phytother Res. 2012. Epub Mar 22.

67. Kwon GT, Jung JI, Song HR, et al. Piceatannol inhibits migration and invasion of prostate cancer cells: possible mediation by decreased interleukin-6 signaling. J Nutr Biochem. 2012;23(3):228-238.

68. Rizzo P, Osipo C, Foreman K, Golde T, Osborne B, Miele L. Rational targeting of Notch signaling in cancer. Oncogene. 2008;27(38): $5124-5131$.

69. Wang XD, Leow CC, Zha J, et al. Notch signaling is required for normal prostatic epithelial cell proliferation and differentiation. Dev Biol. 2006;290(1):66-80.

70. Leong KG, Gao WQ. The Notch pathway in prostate development and cancer. Differentiation. 2008;76(6):699-716.

71. Belandia B, Powell SM, García-Pedrero JM, Walker MM, Bevan CL, Parker MG. Hey 1, a mediator of notch signaling, is an androgen receptor corepressor. Mol Cell Biol. 2005;25(4):1425-1436.

72. Shou J, Ross S, Koeppen H, de Sauvage FJ, Gao WQ. Dynamics of notch expression during murine prostate development and tumorigenesis. Cancer Res. 2001;61(19):7291-7297.

73. Martin DB, Gifford DR, Wright ME, et al. Quantitative proteomic analysis of proteins released by neoplastic prostate epithelium. Cancer Res. 2004;64(1):347-355.

74. Whelan JT, Kellogg A, Shewchuk BM, Hewan-Lowe K, Bertrand FE. Notch-1 signaling is lost in prostate adenocarcinoma and promotes PTEN gene expression. J Cell Biochem. 2009;107(5):992-1001.

75. Santagata S, Demichelis F, Riva A, et al. JAGGED1 expression is associated with prostate cancer metastasis and recurrence. Cancer Res. 2004;64(19):6854-6857.

76. Miele L, Miao H, Nickoloff BJ. NOTCH signaling as a novel cancer therapeutic target. Curr Cancer Drug Targets. 2006;6(4):313-323.

77. Wang Z, Li Y, Banerjee S, et al. Down-regulation of Notch-1 and Jagged-1 inhibits prostate cancer cell growth, migration and invasion, and induces apoptosis via inactivation of Akt, mTOR, and NF-kappaB signaling pathways. J Cell Biochem. 2010;109(4):726-736.

78. Bin Hafeez B, Adhami VM, Asim M, et al. Targeted knockdown of Notch1 inhibits invasion of human prostate cancer cells concomitant with inhibition of matrix metalloproteinase- 9 and urokinase plasminogen activator. Clin Cancer Res. 2009;15(2):452-459.

79. Kong D, Banerjee S, Ahmad A, et al. Epithelial to mesenchymal transition is mechanistically linked with stem cell signatures in prostate cancer cells. PLoS One. 2010;5(8):e12445.

80. Stein MN, DiPaola RS, Mayer TM, et al. A randomized phase II study of bicalutamide (BIC) followed by placebo or gamma secretase inhibitor RO4929097 (RO492) in men with rising PSA. J Clin Oncol. 2012;30(Suppl 5):Abstract 219. 
81. Kim SH, Sehrawat A, Sakao K, Hahm ER, Singh SV. Notch activation by phenethyl isothiocyanate attenuates its inhibitory effect on prostate cancer cell migration. PLoS One. 2011;6(10):e26615.

82. Cancer Institute of New Jersey. Bicalutamide and RO4929097 in treating patients with previously treated prostate cancer. In: ClinicalTrials. gov [website on the Internet]. Bethseda, MD: US National Library of Medicine; 2010 [updated June 21, 2011]. Available from: http:// www.clinicaltrials.gov/ct2/show/NCT01200810. NLM identifier: NCT01200810. Accessed July 17, 2012.

83. Vieweg J. Immunotherapy for advanced prostate cancer. Rev Urol. 2007;9(Suppl 1):S29-S38.

84. Adamo V, Noto L, Franchina T, et al. Emerging targeted therapies for castration-resistant prostate cancer. Front Endocrinol (Lausanne). 2012;3:73.

85. Slovin SR. Toward maximizing immunotherapy in metastatic castrationresistant prostate cancer - rationale for combinatorial approaches using chemotherapy. Front Oncol. 2012;2:43.

86. Moffatt S, Papasakelariou C, Wiehle S, Cristiano R. Successful in vivo tumor targeting of prostate-specific membrane antigen with a highly efficient J591/PEI/DNA molecular conjugate. Gene Ther. 2006;13(9):761-772.

87. Zhang KQ, Yang F, Ye J, et al. A Novel DNA/Peptide Combined Vaccine Induces PSCA-specific Cytotoxic T-lymphocyte Responses and Suppresses Tumor Growth in Experimental Prostate Cancer. Urology. 2012;79(6):1410. e7-1410. e13.
88. van den Eertwegh AJ, Versluis J, van den Berg HP, et al. Combined immunotherapy with granulocyte-macrophage colony-stimulating factor-transduced allogeneic prostate cancer cells and ipilimumab in patients with metastatic castration-resistant prostate cancer: a phase 1 dose-escalation trial. Lancet Oncol. 2012;13(5):509-517.

89. Thakur A, Littrup P, Paul EN, Adam B, Heilbrun LK, Lum LG. Induction of specific cellular and humoral responses against renal cell carcinoma after combination therapy with cryoablation and granulocytemacrophage colony stimulating factor: a pilot study. $J$ Immunother. 2011;34(5):457-467.

90. Drake CG, Antonarakis ES. Current status of immunological approaches for the treatment of prostate cancer. Curr Opin Urol. 2012;22(3): 197-202.

91. Sonpavde G, Di Lorenzo G, Higano CS, Kantoff PW, Madan R, Shore ND. The role of sipuleucel-T in therapy for castration-resistant prostate cancer: a critical analysis of the literature. Eur Urol. 2012;61(4): 639-647.

92. Fishman M. A changing world for DCvax: a PSMA loaded autologous dendritic cell vaccine for prostate cancer. Expert Opin Biol Ther. 2009;9(12):1565-1575.

93. Ward JE, McNeel DG. GVAX: an allogeneic, whole-cell, GM-CSFsecreting cellular immunotherapy for the treatment of prostate cancer. Expert Opin Biol Ther. 2007;7(12):1893-1902.

94. Isaacs JT. The biology of hormone refractory prostate cancer. Why does it develop? Urol Clin North Am. 1999;26(2):263-273.
Biologics: Targets \& Therapy

\section{Publish your work in this journal}

Biologics: Targets \& Therapy is an international, peer-reviewed journal focusing on the patho-physiological rationale for and clinical application of Biologic agents in the management of autoimmune diseases, cancers or other pathologies where a molecular target can be identified. This journal is indexed on PubMed Central, CAS, EMBase, Scopus

\section{Dovepress}

and the Elsevier Bibliographic databases. The manuscript management system is completely online and includes a very quick and fair peerreview system, which is all easy to use. Visit http://www.dovepress. com/testimonials.php to read real quotes from published authors. 